\title{
Dexamethasone bovine pharmacokinetics
}

\author{
Ph. GAIGNAGE ${ }^{1}$, G. LOGNAY ${ }^{1}$, D. BOSSON ${ }^{2}$, D. VERTONGEN ${ }^{2}$, Ph. DREZE ${ }^{3}$, \\ M. MARLIER ${ }^{1}$ and M. SEVERIN ${ }^{1}$ \\ ${ }^{1}$ Department of General and Organic Chemistry, Faculty of Agricultural Sciences, Gembloux, Belgium \\ ${ }^{2}$ Department of Medical Chemistry and Internal Medicine, Saint-Pierre Hospital, Free University of Brussels, Belgium \\ ${ }^{3}$ Department of Physics, Faculty of Agricultural Sciences, Gembloux, Belgium
}

Received for publication : April 26, 1990

Keywords : Dexamethasone, half-life, bovine, plasma, urine

\section{SUMMARY}

Dexamethasone phosphate (DXM-PHO) is an ester which is quickly hydrolysed by the bovine and the dexamethasone (DXM) plasma half-life was $5.16 \mathrm{~h}$. It has been demonstrated that $54 \mathrm{~h}$ after DXM-PHO injection, DXM concentrations were lower than $0.1 \mathrm{mg} / \mathrm{ml}$.

Tritiated dexamethasone was also administered twice to an another young bull for metabolite investigation. The elapsed time required to recover, in plasma, half of the radioactivity injected was $8.8 \mathrm{~h}$. Radioactivity recovery in the urine reached $36.4 \%$ and $22.6 \%$ for the first and the second injections respectively.

\section{INTRODUCTION}

Dexamethasone (DXM) and dexamethasone esters (phenylpropionate, sodium-phosphate, isonicotinate) are among the most potent fluorinated synthetic glucocoritcoids widely used in human and veterinary practice for their anti-inflammatory, anti-allergic and anti-rheumatic properties. For several years, it has been known that these compounds have also been illicitly administered as 'hormones' to improve the phenotype of beef catle at the end of the fattening period $(1,2)$.

The accumulation of such molecules and their metabolites in organs and meat could represent a potential hazard for the consumer's bealth which is still difficult to evaluate. Investigations of residues (in plasma and urine) are not easy due to the many interfering compounds resulting from general metabolism of the animal. Moreover, other factors

Please send reprint requests to : $\mathrm{Mr} \mathrm{Ph}$. Gaignage, Department of General and Organic Chemistry, Faculty of Agricultural Sciences, 2 Passage des Déportés, B-5800 Gembloux, Belgium such as the misreading of the drug, the low quantities injected, the number of treatments, the delay between the injection and slaughtering and the nature of the treatment (intramuscular, intravenous, or others) can considerably affect the possibilities of detecting traces of these molecules.

This paper describes the study, by radioimmunoassay (RIA), of the DXM sodium-phosphate (DXMPHO) phannacokinetics in young cattle. Plasma half-life of the DXM, liberated from the ester, and the period in which DXM is still detectable have been determined. In further investigations on DXM metabolism, tritiated DXM was administered to another bull. Pharmacokinetics of the total radioactivity (tritiated DXM + related tritiated compounds) have also been studied and recovery of radioactive compounds from the urine was assessed.

\section{MATERIALS AND METHODS}

Plasma DXM concentrations were determined by RIA following the method described by Lejeune-Lenain et 

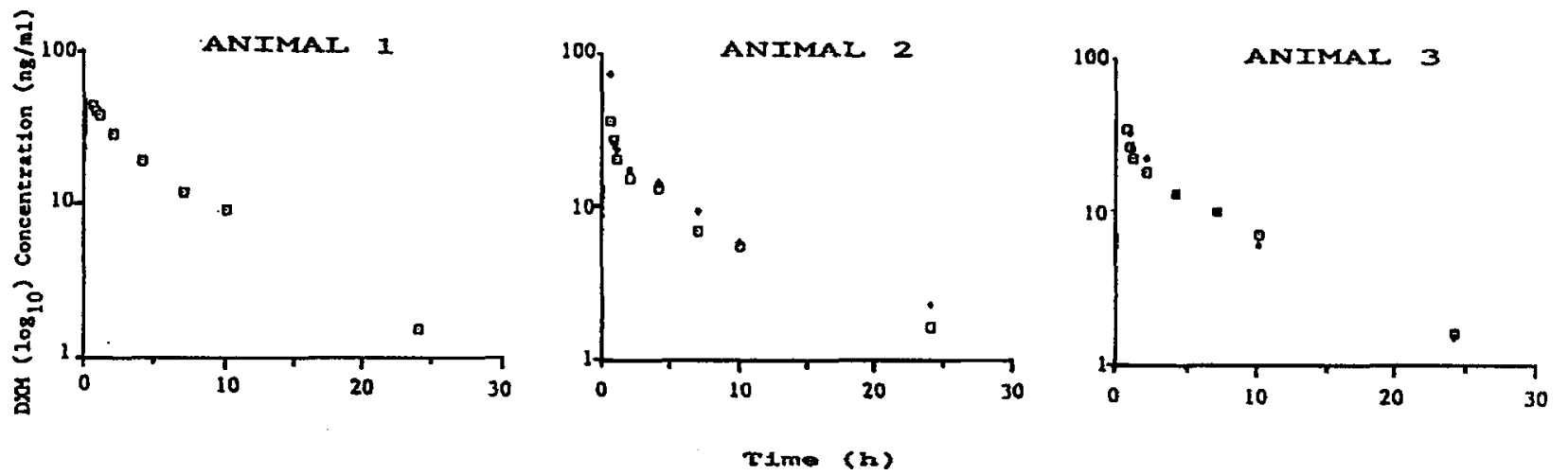

Fig. 1 : Semi-logarithmic plots of the disposition curve of dexamethasone phosphate in bovine plasma Open squares - first injection, filled diamonds - second injection

al. (3). Cross-reactivities with the main endogenous steroids (including cortisol) were lower than $0.1 \%$.

\section{Chemicals}

Dexamethasone (DXM) was purchased from Steraloïds, the monoclonal antiserum against DXM, from IgG Corporation (Nashville, USA) and dexamethasone-21-Na-phosphate (DXM-PHO), (Decadron) from Merck Sharp and Dohme (Germany). Labelled $\left.1,2,4-{ }^{3} \mathrm{H}\right]-\mathrm{DXM}$ was purchased from Amersham (UK: code number $=$ TRK 417).

\section{Animals}

Two young Pie-Noir bulls weighing $280 \mathrm{~kg}$ (animal 1, experiment I) and $235 \mathrm{~kg}$ (animal 4, experiment I) and identical Pie-Noir cattle twins weighing $124 \mathrm{~kg}$ (animal 2, experiment I) and $132 \mathrm{~kg}$ (animal 3, experiment I) were placed in metabolism boxes and allowed hay, granules and water ad libitum.

\section{Treatments and sampling}

Decadron ( $0.1 \mathrm{mg} / \mathrm{kg}$ body weight) was injected in the left jugular vein and the animals were catheterized in the right jugular vein to minimize disturbances during blood sampling. Blood samples $(10 \mathrm{ml})$ were collected at frequent intervals on the first day, put into ice-cold heparinized tubes and immediately centrifuged.

Animal 4 was injected first with $400 \mu \mathrm{Ci}$ of tritiated DXM and 9 days later with $483 \mu \mathrm{C}$. Radioactive plasma and urine samples were directly transferred to scintillation vials. After addition of $10 \mathrm{ml}$ of scintillation liquid (Lumagel), vials were counted for $10 \mathrm{~min}$ in a Beckman (No. LS 7500) B-scintillator. Blanks were collected from the same animal before treatment.

\section{RESULTS AND DISCUSSION}

\section{Experiment 1: DXM-PHO in plasma}

DXM plasma concentrations are shown in semilogarithmic plots (Fig. 1). Maximum levels (> $700 \mathrm{ng}$ $\mathrm{DXM} / \mathrm{ml}$ plasma) occurred during the first $15 \mathrm{~min}$ following the administration. After $30 \mathrm{~min}$, and for five consecutive experiments, DXM concentrations decreased very sharply and showed values ranging from 72-20 $\mathrm{ng} / \mathrm{ml}$ plasma.

Semi-logarithmic regression analyses gave $5.46 \mathrm{~h}$ as the mean plasma half-life ( $S D=0.26, \mathrm{n}=5$ ).

In each experiment, DXM concentrations were below $0.1 \mathrm{ng} / \mathrm{ml}, 54 \mathrm{~h}$ post-injection. Pharmacokinetics were established on the basis of 8 DXM RIA values and each measurement was repeated 3 times.

In dairy cows, Fairclough et al. (4) demonstrated that a $20 \mathrm{mg}$ DXM-PHO intramuscular injection led to 70-24 ng/ml plasma maximum levels within 2-20 min and DXM concentrations were lower than $0.15 \mathrm{ng} / \mathrm{ml}$ after $72 \mathrm{~h}$.

The results of our study agree very well with those of Tainturier et al. (5), who calculated a $4.5 \mathrm{~h}$ plasma half-life after a $0.1 \mathrm{mg} / \mathrm{kg}$ DXM isonicotinate intravenous injection to dairy cows. In cattle, Toutain et al. (6) observed 5.58 and $4.5 \mathrm{~h}$ plasma half-life after $D X M$ and DXM isonicotinate intravenous injection, respectively. 


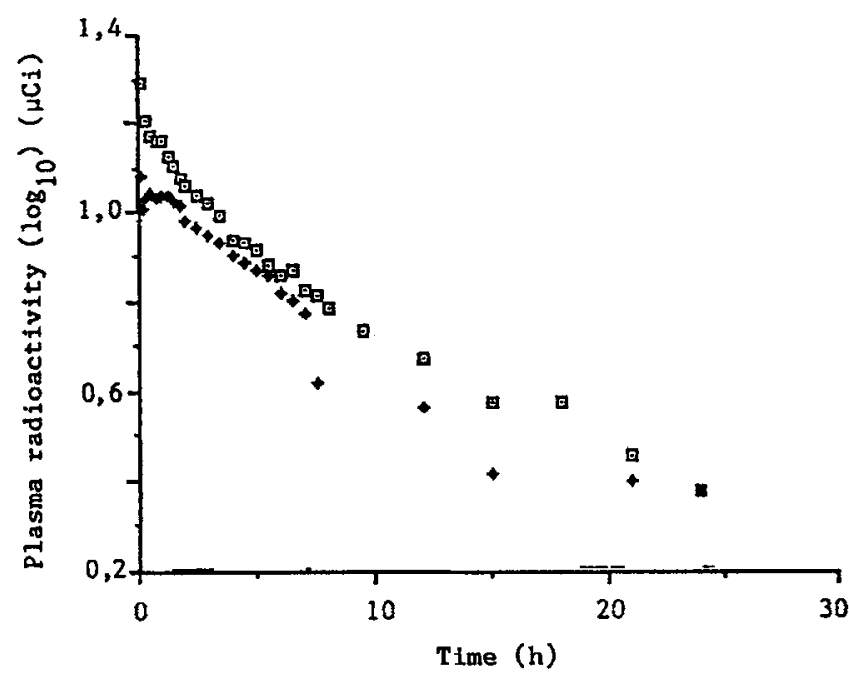

Fig. 2 : Semi-logarithmic plots of the elimination of radioactivity (DXM + related compounds) in bovine plasma

Open squares $=$ first injection

Filled diamonds $=$ second injection

\section{Experiment II: Tritiated DXM in plasma and urine}

Pharmacokinetics I and II (on total radioactivity) were determined with 27 and 25 values respectively (Fig. 2).

Maximum radioactivity levels in plasma occurred during the first $15 \mathrm{~min}$ following the two injections and the residual radioactivity was estimated at 0.09 $\mu \mathrm{Ci}(0.02 \%$ of $400 \mu \mathrm{Ci}$ administered) just before the second injection.

For both pharmacokinetics, the radioactivity levels declined very slowly to become insignificant $(<0.05$ $\mu \mathrm{Ci}), 11$ days after the second treatment.

During the first $24 \mathrm{~h}$, the elapsed time to recover half of the radioactivity was $8.8 \mathrm{~h}$ for both injections. This value, higher than that obtained for DXM, is a global measurement involving tritiated DXM and other related tritiated compounds produced, particularly DXM metabolites. In addition to the two blood sampling periods ( 9 and 12 days), urine samples were also collected in order to estimate the radioactivity excreted daily (Fig. 3).

The total cumulative radioactivity recovered in urine $216 \mathrm{~h}$ after the administration, was $36.4 \%$ (first injection) and $22.6 \%$ (second injection). The number and the identification of DXM metabolites will be reported later.

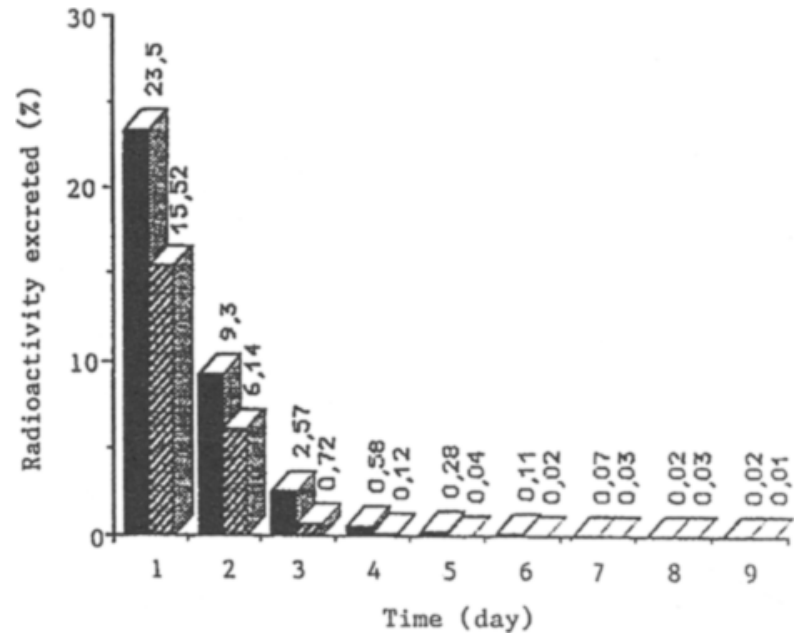

Fig. 3 : Radioactivity recovery in bovine urine following two intravenous injections of tritiated dexamethasone Solid area $=$ first injection Hatched area $=$ second injection

\section{ACKNOWLEDGEMENTS}

The authors acknowledge the technical assistance of C. Charlier and $\mathrm{N}$. Hung. This research was financially supported by IRSIA (Institut pour la Recherche Scientifique dans l'Industrie et l'Agriculture).

\section{REFERENCES}

1. Lognay G., Marlier M., Renaville R., Severin M. (1987) : Sequential analysis of preparations promoting the zootechnical performances in cattle. Rec. Med. Vet, 163, 655-660.

2. Gaignage Ph., Lognay G., Marlier M., Severin M., Dreze Ph. (1989) : Applications of chromatographic and spectrometric techniques to the study of dexamethasone related compounds. Chromatographia, 28, 623-630.

3. Lejeune-Lenain C., Kina S., Bosson D. (1987) : Preparative HPLC for analysis of mineralocorticoids in human plasma. Chromatographia, 24, 333-338.

4. Fainclough R.J., Hunter J.T., Welch R.A.S. (1981) : Dexamethasone concentrations in plasma and milk of cows following the injection of long and short acting dexamethasone esters. Aust. J. Biol. Sci., 34, 313-319.

5. Tainturier D., Alvinerie M., Brandon R.A., Toutain P.L. (1981) : Dexamethasone concentrations in bovine blood plasma and milk after intravenous injection. J. Dairy Sci., 65, 1921-1924.

6. Toutain P.L., Brandon R.A., Alvinerie M., Garcia-Villar R., Ruchebusch Y. (1982) : Dexamethasone in cattle: pharmacokinetics and action on the adrenal gland. J. Vet Pharmacol. Therap., 5, 33-43. 